\title{
W-Band Hybrid Unequal Feeding Network of Waveguide and Substrate Integrated Waveguide for High Efficiency and Low Sidelobe Level Slot Array Antenna Application
}

\author{
Jun Wang and Yu Jian Cheng \\ EHF Key Lab of Fundamental Science, School of Electronic Engineering, University of Electronic Science and Technology of China, \\ Xiyuan Road 2006, Chengdu 611731, China \\ Correspondence should be addressed to Yu Jian Cheng; chengyujian@uestc.edu.cn
}

Received 13 December 2016; Revised 17 February 2017; Accepted 23 February 2017; Published 8 March 2017

Academic Editor: Paolo Baccarelli

Copyright (C) 2017 Jun Wang and Yu Jian Cheng. This is an open access article distributed under the Creative Commons Attribution License, which permits unrestricted use, distribution, and reproduction in any medium, provided the original work is properly cited.

\begin{abstract}
A W-band hybrid unequal feeding network of waveguide and substrate integrated waveguide (SIW) is presented in this paper. It comprises a two-way hybrid waveguide-SIW E-plane divider and an unequal SIW dividing network. Firstly, the two-way hybrid divider is developed to realize the waveguide-to-SIW vertical transition and power division at the same time. Besides, it has a wider bandwidth and more compact configuration compared with those of conventional structures including a transition and a cascading divider. Secondly, an SIW 1-to-16-way unequal dividing network is developed with the phase self-compensation ability. This W-band dividing network is able to generate the desired amplitude and phase distribution. Finally, two back-to-back SIW 16 $\times 16$ antenna arrays are grouped and fed by the proposed feeding network. The low sidelobe levels (SLLs) can be achieved at Eand H-plane of the antenna. The total aperture size of the antenna is $15 \%$ less than that of a conventional antenna with a separated divider and a transition. With such a multifunctional feeding network, the antenna is able to achieve low loss and high efficiency as well.
\end{abstract}

\section{Introduction}

In recent years, $\mathrm{W}$-band applications have attracted great attention for gigabyte point-to-point data transmission, radar, and imaging systems $[1,2]$. Combining excellent features of planar transmission lines and nonplanar waveguide, substrate integrated waveguide (SIW) [3-6] has become a good option for $\mathrm{W}$-band circuit and antenna designs. In this paper, an SIW array antenna operating from $93 \mathrm{GHz}$ to $95 \mathrm{GHz}$ with high efficiency and low sidelobe level (SLL) is presented.

A low SLL linear slot array antenna can be synthesized by methods described in $[7,8]$. To obtain the low SLL in the orthogonal plane, an unequal feeding network is necessary to produce the required array excitation. There are various types of unequal dividers based on the SIW technology [9-13]. However, these structures are difficult to be applied in W-band designs considering relatively large metallic vias compared to W-band SIW dimension. Hence, an unequal dividing network without additional phase shifters is introduced to generate the desired amplitude and phase distribution.

In this work, a $16 \times 32$ antenna array can satisfy the gain requirement but cannot satisfy the bandwidth requirement. Thus, this array should be separated into two $16 \times 16$ subarrays to widen the bandwidth [14]. In this case, a long SIW feedline is necessary to connect two subarrays, leading to unacceptable loss [15]. Thus, a proper waveguide divider should be used in the feeding network to reduce loss and improve total efficiency of the antenna array. A typical design includes a separated SIW divider, an SIW-to-waveguide transition, and a waveguide divider, which are connected one by one $[1,16-$ 18]. It results in large circuit area, high loss, and narrow bandwidth. Hence, a compact hybrid waveguide-SIW Eplane divider is proposed. It is able to realize the waveguideto-SIW vertical transition and two-way power division at the same time. Thus, the total circuit area of the antenna array can be approximately reduced by $15 \%$. Simultaneously, the return 


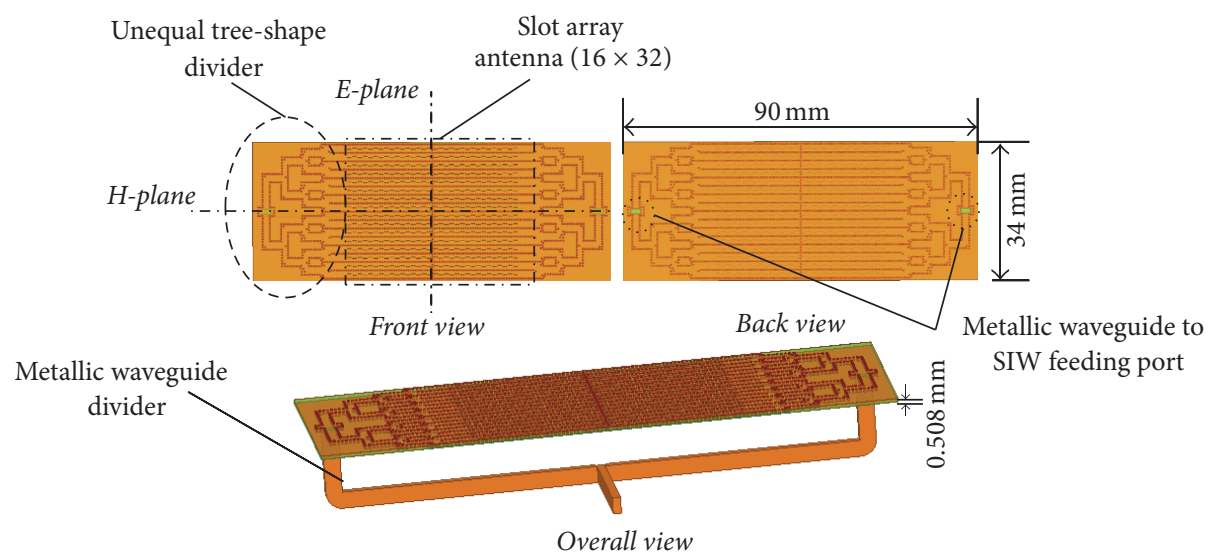

FIGURE 1: Configuration of the SIW antenna and the feeding network.

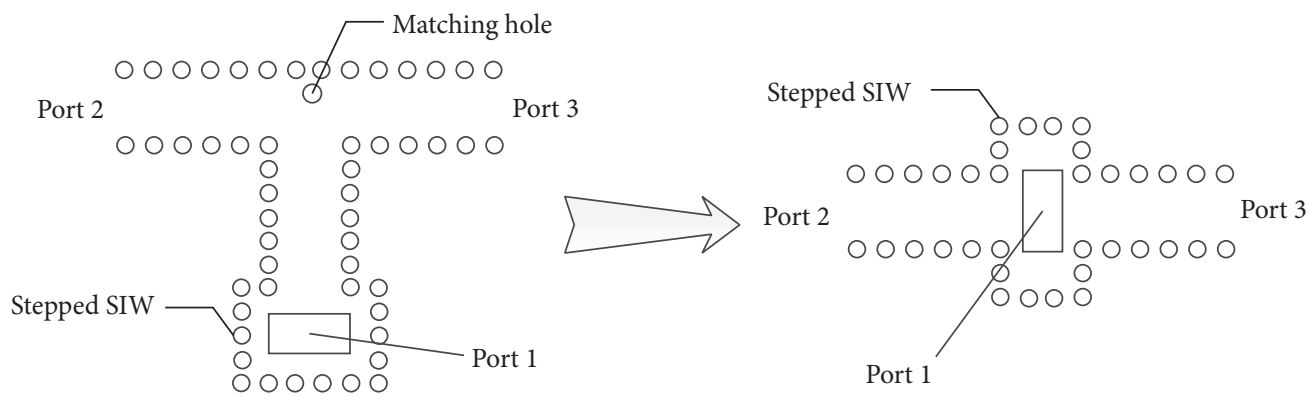

(a)

(b)

FIGURE 2: Different types of waveguide-SIW dividers. (a) Conventional structure; (b) proposed hybrid E-plane divider.

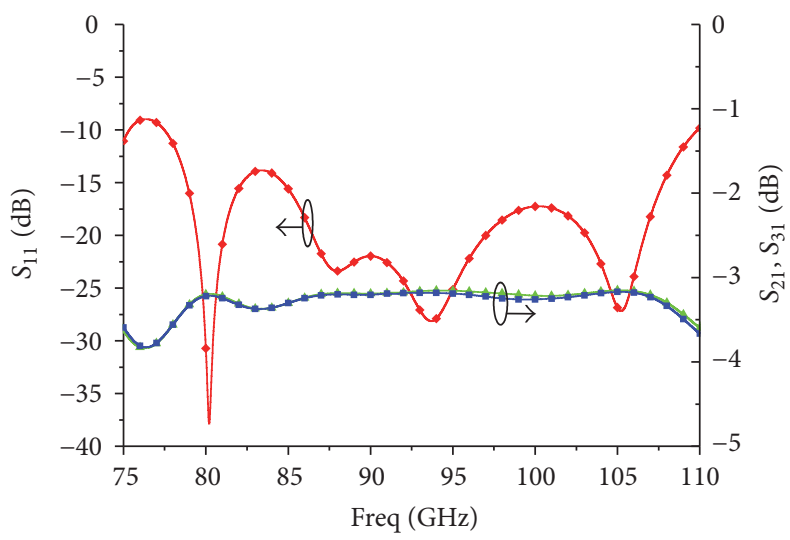

(a)

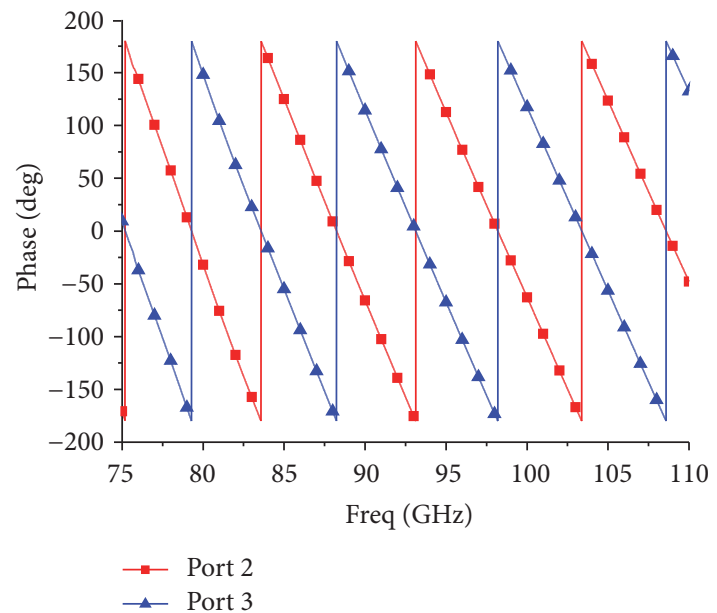

(b)

FIgURE 3: (a) S-parameters of the proposed hybrid waveguide-SIW E-plane divider; (b) phase output of the proposed hybrid waveguide-SIW E-plane divider.

loss of the divider is less than $-15 \mathrm{~dB}$ from $85 \mathrm{GHz}$ to $107 \mathrm{GHz}$. The bandwidth of the typical design in [1] is only from $90 \mathrm{GHz}$ to $98 \mathrm{GHz}$.

Finally, an SIW-based slot array antenna fed by the proposed hybrid feeding network is fabricated. Simulated and measured results are in good agreement.

\section{Design}

2.1. Configuration. As shown in Figure 1 , two $16 \times 16$ SIW slot array antennas are placed back-to-back in a single-layer Rogers 5880 substrate with $\varepsilon_{r}=2.2$ and $\tan \delta=0.0009$. The total size of the PCB board is $34 \times 90 \times 0.508 \mathrm{~mm}^{3}$. An 


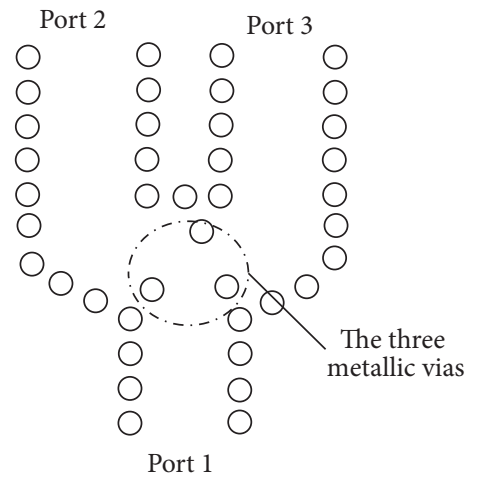

(a)

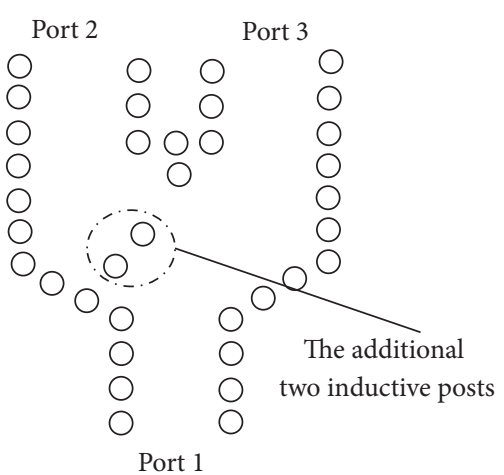

(b)

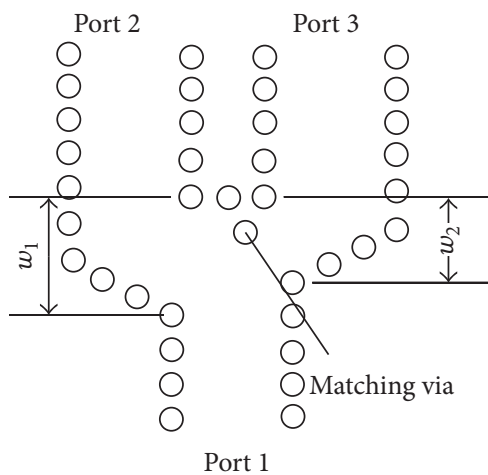

(c)

FIGURE 4: Different types of unequal dividers. (a) Structure in [9]; (b) structure in [10]; (c) our structure.

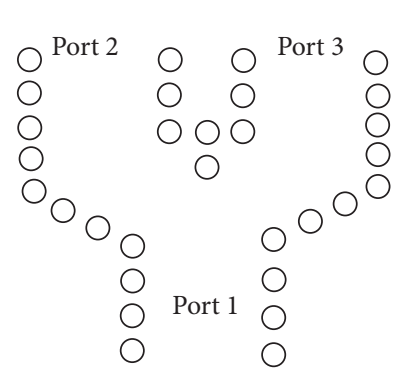

(a) First step

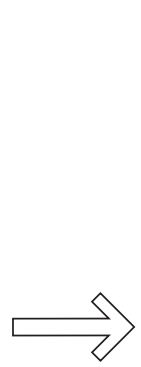

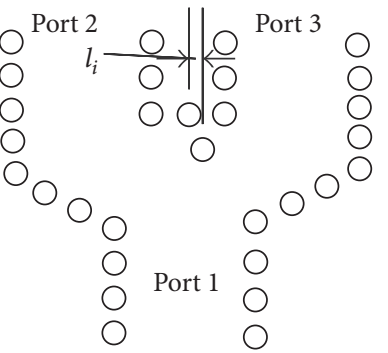

(b) Second step

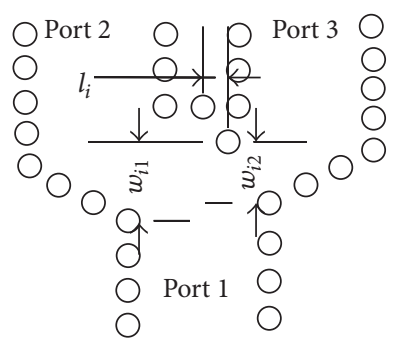

(d) Last step

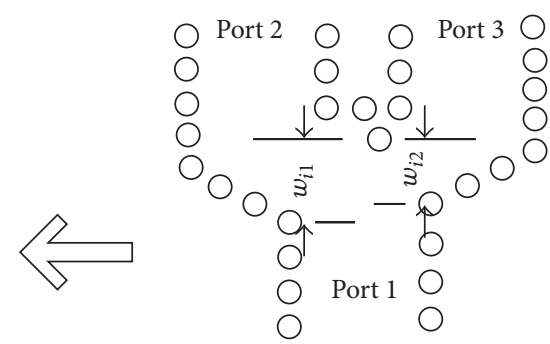

(c) Third step

FIGURE 5: Design process of the proposed unequal divider.

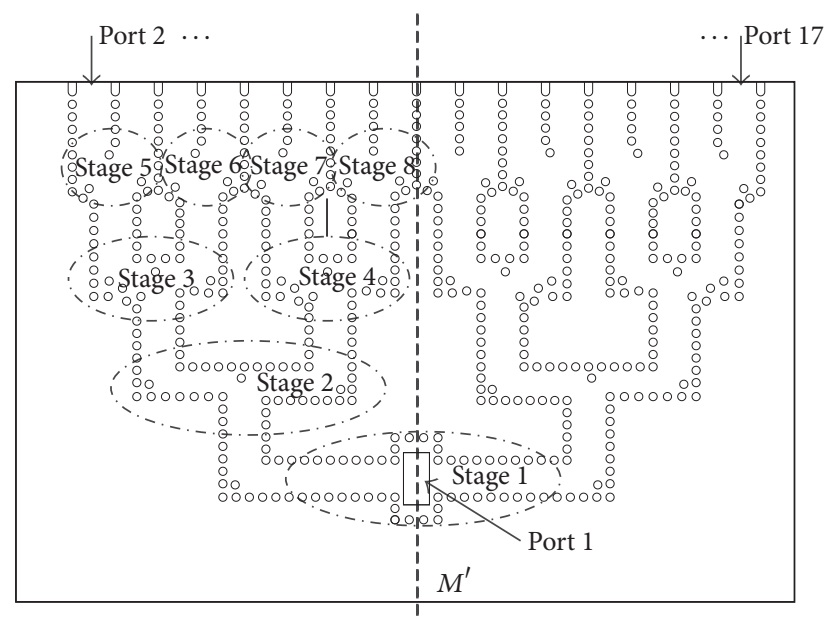

FIGURE 6: Configuration of the sixteen-way unequal feeding network. 


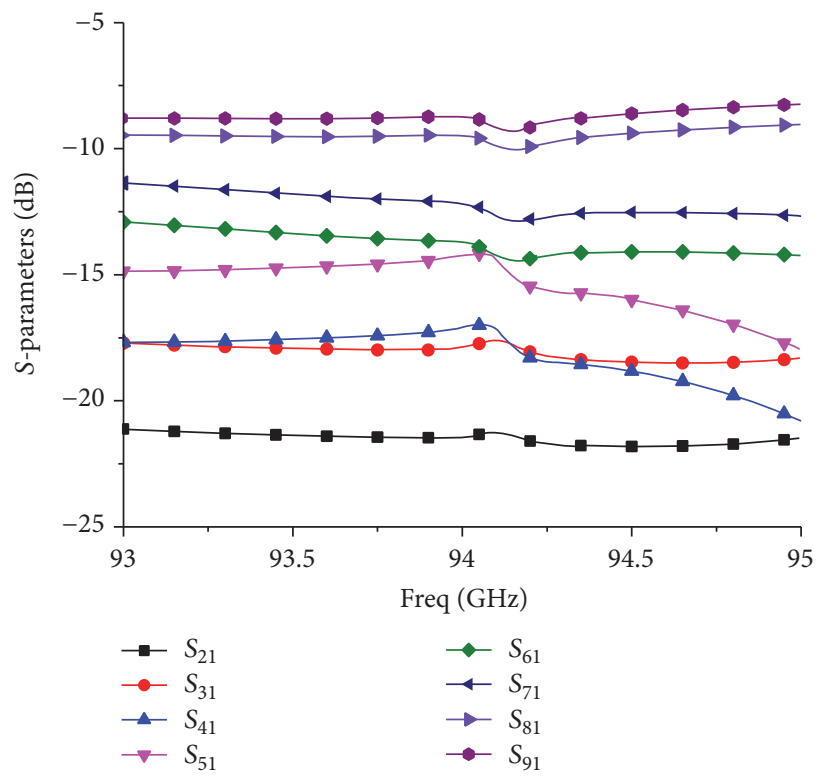

(a)

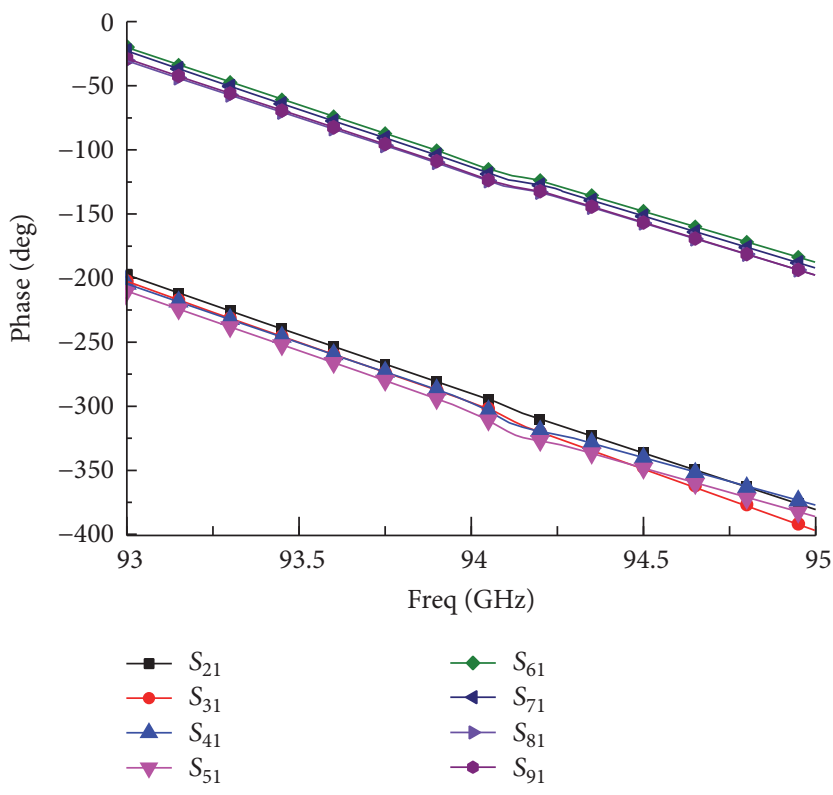

(b)

Figure 7: (a) Transmission coefficient of the sixteen-way feeding network. (b) Phase distribution of the sixteen-way feeding network.

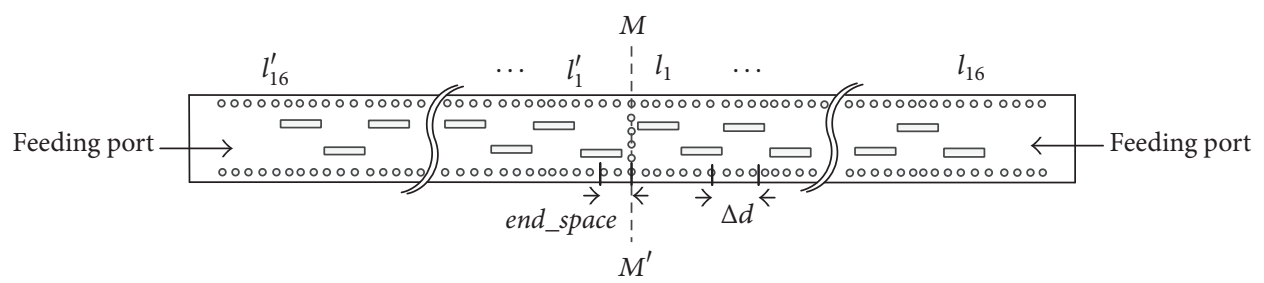

FIGURE 8: Configuration of the back-to-back SIW slot array antenna (end_space $=0.818 \mathrm{~mm}$, and $\Delta d=1.335 \mathrm{~mm}$ ).

SIW feeding structure is employed to excite sixteen low SLL linear slot antennas with proper amplitude and phase. The width of the SIW is $2.1 \mathrm{~mm}$, the diameter of the metallized via is $0.4 \mathrm{~mm}$, and the distance between two adjacent vias is $0.6 \mathrm{~mm}$. In order to reduce the dielectric loss and increase the radiation efficiency, a hybrid waveguide-SIW E-plane divider is used to connect two SIW arrays together. The height of the hybrid divider is $34 \mathrm{~mm}$, which can be reduced much more by use of a reduced-height waveguide divider. The operating frequency of the antenna is from $93 \mathrm{GHz}$ to $95 \mathrm{GHz}$.

\subsection{Design Process}

2.2.1. Hybrid Waveguide-SIW E-Plane Divider. To increase feeding efficiency at W-band, a hybrid feeding network of SIW and waveguide is employed. Firstly, the SIW-based divider is used to feed the sixteen-element antenna. After that, the waveguide-based divider is used to feed two SIWbased dividers to avoid the use of long SIW branches. In this case, a waveguide-to-SIW transition is necessary between the SIW-based and the waveguide-based dividers. A separated waveguide-to-SIW transition is typically used in conventional designs as shown in Figure 2(a). It has a larger area compared with the proposed hybrid waveguide-SIW E-plane divider as shown in Figure 2(b). A coupled aperture is etched on the top conductor layer of the SIW. The stepped SIW is used to improve the matching characteristic. It is able to realize the waveguide-to-SIW vertical transition and 1to-2 power division at the same time. Simultaneously, the difference between the output phases of port 2 and port 3 as shown in Figure 2(b) is $180^{\circ}$ over a wide frequency range. It can be applied for wideband differential feeding structures. Such a functional integration configuration leads to low loss and high efficiency.

The simulated $S$-parameters of the proposed hybrid Eplane divider are shown in Figure 3(a). The return loss is below $-15 \mathrm{~dB}$ from $85 \mathrm{GHz}$ to $107 \mathrm{GHz}$, and the insertion loss is less than $0.3 \mathrm{~dB}$. As shown in Figure 3(b), the phase difference between port 2 and port 3 is about $180^{\circ}$ and the phase error is less than $1^{\circ}$ over the whole $\mathrm{W}$-band. Table 1 presents the compared results between our work and other waveguide-SIW structures. As listed in Table 1, the bandwidth of our design is much wider than that in [1] with a similar configuration in Figure 2(a). In [16], it is a transition and the relative bandwidth is $16.7 \%$, which is also less than that of our design. In addition, the W-band SIW has more strict design rule to avoid high fabrication tolerance and radiation leakage 
TABLE 1: Comparison between different waveguide-SIW dividers and waveguide-to-SIW transitions.

\begin{tabular}{lcccc}
\hline & Processing & Configuration & Bandwidth $\left(S_{11}<15\right.$ dB $)$ & Relative bandwidth \\
\hline Our work & PCB, single layer & Transition + divider & $85 \sim 107 \mathrm{GHz}$ & $22.9 \%$ \\
{$[1]$} & PCB, single layer & Transition + divider & $90 \sim 98 \mathrm{GHz}$ & $8.5 \%$ \\
{$[16]$} & PCB, single layer & Transition & $55 \sim 65 \mathrm{GHz}$ & $16.7 \%$ \\
{$[17]$} & LTCC, multiple layer & Transition & $82 \sim 100 \mathrm{GHz}$ & $19.7 \%$ \\
{$[18]$} & PCB, multiple layer & Transition & $55 \sim 65 \mathrm{GHz}$ & $16.7 \%$ \\
\hline
\end{tabular}

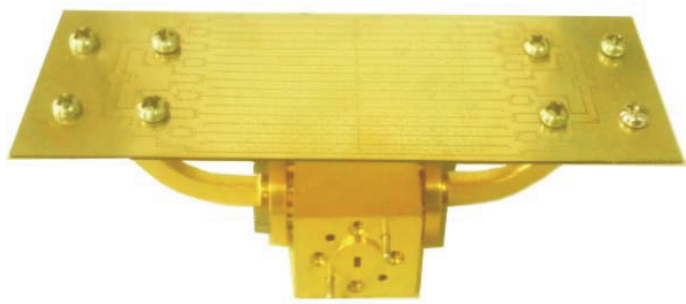

FIGURE 9: Photograph of the fabricated antenna.

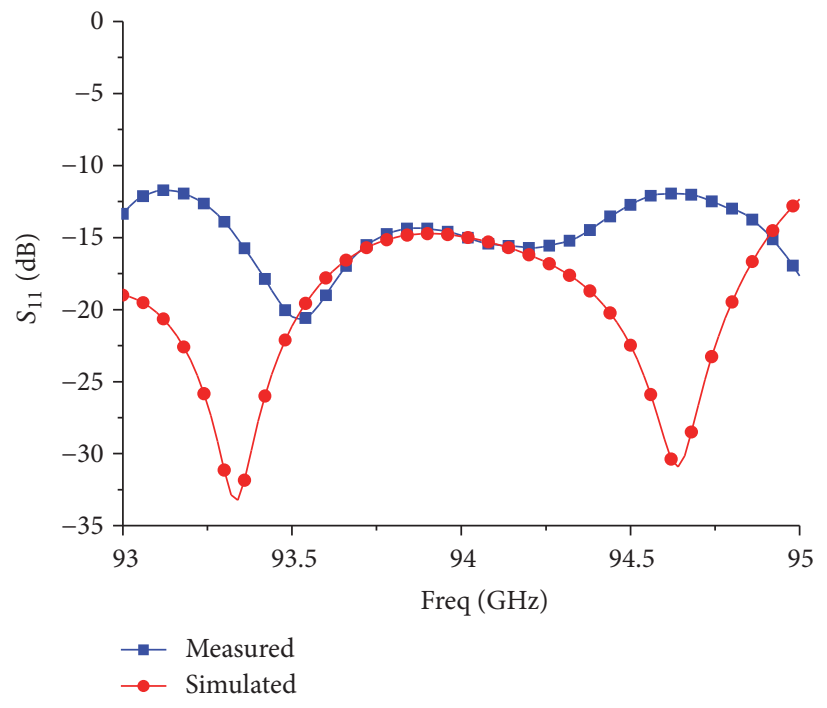

(a)

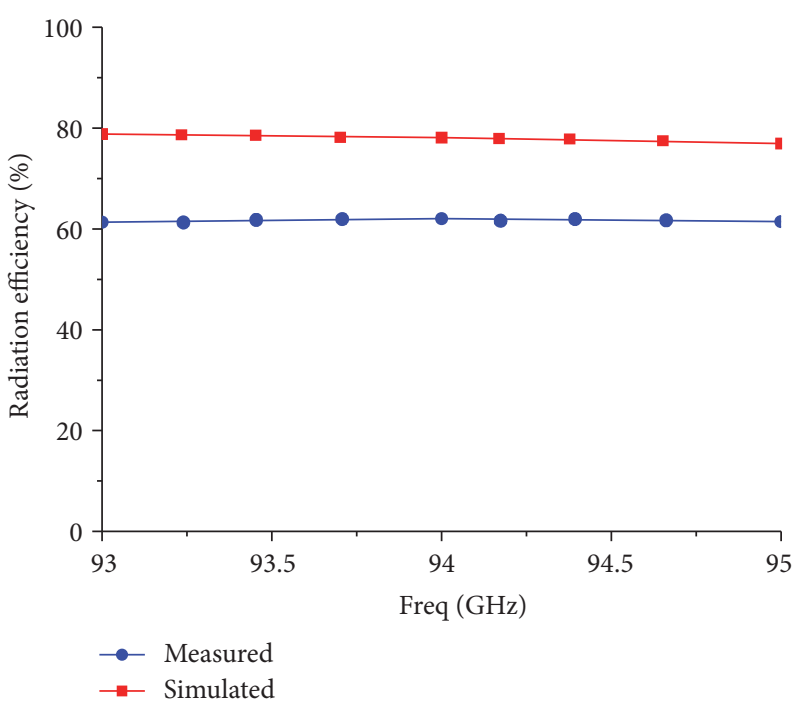

(b)

FIgURE 10: (a) Return loss of the fabricated antenna. (b) Radiation efficiency of the antenna.

compared with those designs at a lower frequency band. In $[17,18]$, the multiple-layer transition structures based on PCB and LTCC are introduced. However, they are difficult to fabricate. Their bandwidths are relatively narrow as well. In conclusion, our design is more suitable for high-frequency and wideband designs.

2.2.2. Unequal SIW Divider. To achieve the shaped beam in E-plane of the array antenna as shown in Figure 1, an unequal divider should be employed as described before. Generally speaking, the unequal divider should have the tapered amplitude output and keep in-phase or out-of-phase output at the same time.
There are various types of unequal dividers based on the SIW technology [9-13]. Reference [11] introduced an unequal SIW power divider. The phase balance was realized by different path lengths of the SIW. Nevertheless, it is not compact and has a narrow bandwidth. In [12], a compact combshape unequal divider with phase balance was presented. It is difficult to design and also has a narrow bandwidth with the increase of the feeding network scale. In [9], a $K_{a}$-band unequal SIW T-junction divider was proposed. Different weighting ratio and phase balance can be obtained for each output port by controlling the position of three metallic vias in the T-junction as shown in Figure 4(a). Reference [10] introduced a C-band wideband unequal divider by two additional inductive posts in the T-junction, as shown in 
TABLE 2: Parameters of different T-junction unequal dividers (unit: $\mathrm{mm})$.

\begin{tabular}{lc}
\hline$w_{21}$ & 1.64 \\
$w_{22}$ & 1.45 \\
$w_{31}$ & 1.86 \\
$w_{32}$ & 1.68 \\
$w_{41}$ & 1.85 \\
$w_{42}$ & 1.68 \\
$w_{51}$ & 1.85 \\
$w_{52}$ & 1.68 \\
$w_{61}$ & 1.64 \\
$w_{62}$ & 1.3 \\
$w_{71}$ & 1.54 \\
$w_{72}$ & 1.3 \\
$w_{81}$ & 1.54 \\
$w_{82}$ & 1.46 \\
$l_{2}$ & 0.15 \\
$l_{3}$ & 0.21 \\
$l_{4}$ & 0.21 \\
$l_{5}$ & 0.6 \\
$l_{6}$ & 0.6 \\
$l_{7}$ & 0.6 \\
$l_{8}$ & 0 \\
\hline
\end{tabular}

TABLE 3: Simulated results of each stage single T-junction unequal divider.

\begin{tabular}{lcc}
\hline & Power division ratio & Output phase difference \\
\hline Stage 1 & $1: 1$ & $180^{\circ} \pm 1^{\circ}$ \\
Stage 2 & $3.66: 1$ & $180^{\circ} \pm 3^{\circ}$ \\
Stage 3 & $2.27: 1$ & $0^{\circ} \pm 2^{\circ}$ \\
Stage 4 & $1.57: 1$ & $0^{\circ} \pm 2^{\circ}$ \\
Stage 5 & $1.15: 1$ & $0^{\circ} \pm 2^{\circ}$ \\
Stage 6 & $1.55: 1$ & $0^{\circ} \pm 2^{\circ}$ \\
Stage 7 & $1.32: 1$ & $0^{\circ} \pm 2^{\circ}$ \\
Stage 8 & $1.11: 1$ & $0^{\circ} \pm 2^{\circ}$ \\
\hline
\end{tabular}

Figure 4(b). However, these methods in $[9,10]$ are difficult to be applied in $\mathrm{W}$-band designs considering the large metallic via relative for the $\mathrm{W}$-band SIW dimension. Here, an unequal dividing network without additional phase shifters is introduced to overcome these weaknesses. The basic T-junction divider is shown in Figure 4(c). By changing the position of the matching via and the width of two SIW arms $w_{1}$ and $w_{2}$, unequal power division ratio and phase balance output can be achieved. Theoretically, this design is not limited by the scale of the feeding network and the operating frequency.

The design steps of the unequal T-junction divider are shown in Figure 5. Firstly, an equal divider is designed with good impedance matching. Secondly, the center post is moved with $l_{i}(i=2,3, \ldots, 8)$ to realize unequal power division between port 2 and port 3 . In this case, there exists a phase difference between port 2 and port 3 . Thirdly, the widths of two arms $w_{i 1}$ and $w_{i 2}(i=2,3, \ldots, 8)$ are modified to realize the same phase output at port 2 and port 3 . After
TABLE 4: Slot length of a synthesized low SLL SIW slot antenna (unit: $\mathrm{mm})$.

\begin{tabular}{lc}
\hline$l_{1}\left(l_{1}^{\prime}\right)$ & 1.137 \\
$l_{2}\left(l_{2}^{\prime}\right)$ & 1.132 \\
$l_{3}\left(l_{3}^{\prime}\right)$ & 1.127 \\
$l_{4}\left(l_{4}^{\prime}\right)$ & 1.121 \\
$l_{5}\left(l_{5}^{\prime}\right)$ & 1.116 \\
$l_{6}\left(l_{6}^{\prime}\right)$ & 1.111 \\
$l_{7}\left(l_{7}^{\prime}\right)$ & 1.105 \\
$l_{8}\left(l_{8}^{\prime}\right)$ & 1.100 \\
$l_{9}\left(l_{9}^{\prime}\right)$ & 1.089 \\
$l_{10}\left(l_{10}^{\prime}\right)$ & 1.083 \\
$l_{11}\left(l_{11}^{\prime}\right)$ & 1.074 \\
$l_{12}\left(l_{12}^{\prime}\right)$ & 1.066 \\
$l_{13}\left(l_{13}^{\prime}\right)$ & 1.055 \\
$l_{14}\left(l_{14}^{\prime}\right)$ & 1.052 \\
$l_{15}\left(l_{15}^{\prime}\right)$ & 1.01 \\
$l_{16}\left(l_{16}^{\prime}\right)$ & 0.968 \\
\hline
\end{tabular}

these steps, the matching of the divider may become poor. In the last step, the center post and the widths of port 2 and port 3 should be adjusted slightly to achieve better matching.

In this design, there is a sixteen-way unequal divider with $-25 \mathrm{~dB}$ Taylor output distribution. The divider is symmetric with the center line $M-M^{\prime}$ as shown in Figure 6. The whole feeding network consists of eight T-junction dividers. They include one equal T-junction divider and seven unequal $\mathrm{T}$ junction dividers. Parameters of different T-junction unequal dividers are given in Table 2. Simulated results of each stage single $\mathrm{T}$-junction unequal divider are given in Table 3 . This type of unequal divider can keep the in-phase or out-of-phase output without additional phase shifters.

The transmission coefficients of the optimized feeding network at different output ports are depicted in Figure 7(a). The output phases at different output ports are given in Figure $7(\mathrm{~b})$. The phases of ports $2 \sim 5$ or ports $6 \sim 9$ are the same. However, the phase is reverse between ports $2 \sim 5$ and ports $6 \sim 9$. It can be compensated by changing the antenna placement, that is, the offset direction of the slot, to realize the same phase distribution. The simulated result shows that the phase difference between different ports is about $\pm 5^{\circ}$.

2.2.3. SIW Slot Array Antenna. As is shown in Figure 8, there is a 32-slot antenna with two 16-slot antennas placed back-to-back. The 32-slot antenna is fed by two ports at the same time. The lengths of slots are $l_{1}, \ldots, l_{i}, \ldots, l_{16}$ and $l_{1}^{\prime}, \ldots, l_{i}^{\prime}, \ldots, l_{16}^{\prime}$. The distance, end_space, from the center of the first slot to the symmetrical plane $M-M^{\prime}$, is about $\lambda_{g} / 4$. The distance between two adjacent slots, $\Delta d$, is about $\lambda_{g}^{g} / 2$. $\lambda_{g}$ is the guided-wavelength in the SIW. In order to simplify the design process, all slot offsets are the same. Initial length of each slot can be calculated by Elliott's iterative procedure and optimized by the full-wave simulation. The final length of each slot is given in Table 4. 


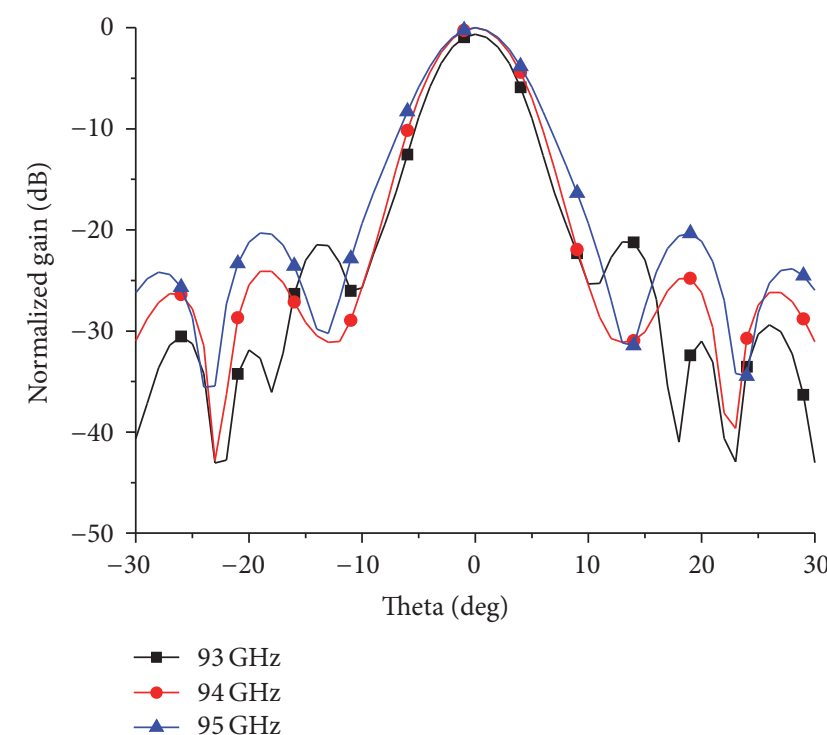

(a)

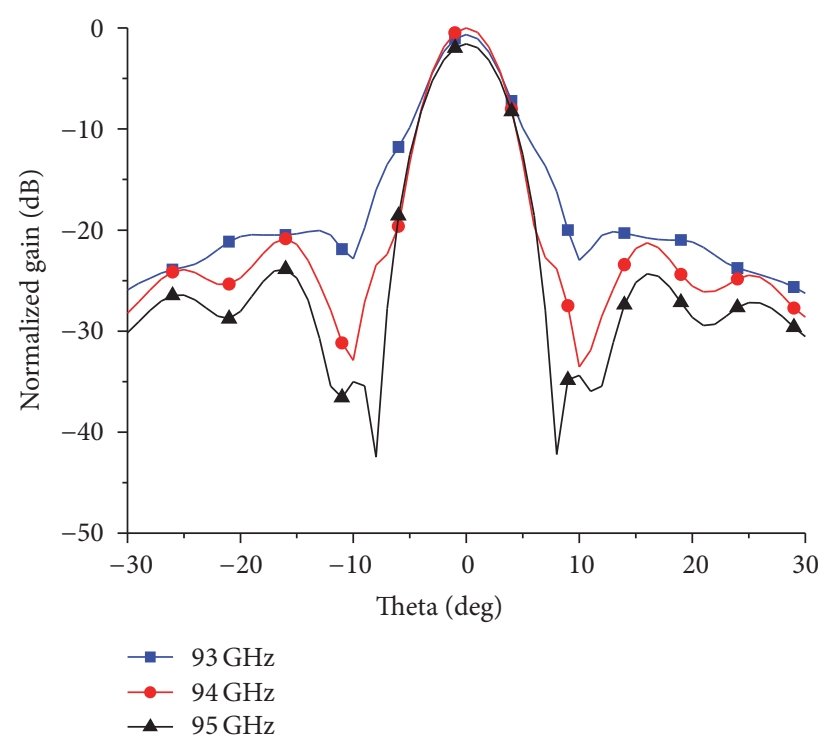

(b)

FIGURE 11: Simulated radiation patterns at different frequencies. (a) E-plane; (b) H-plane.

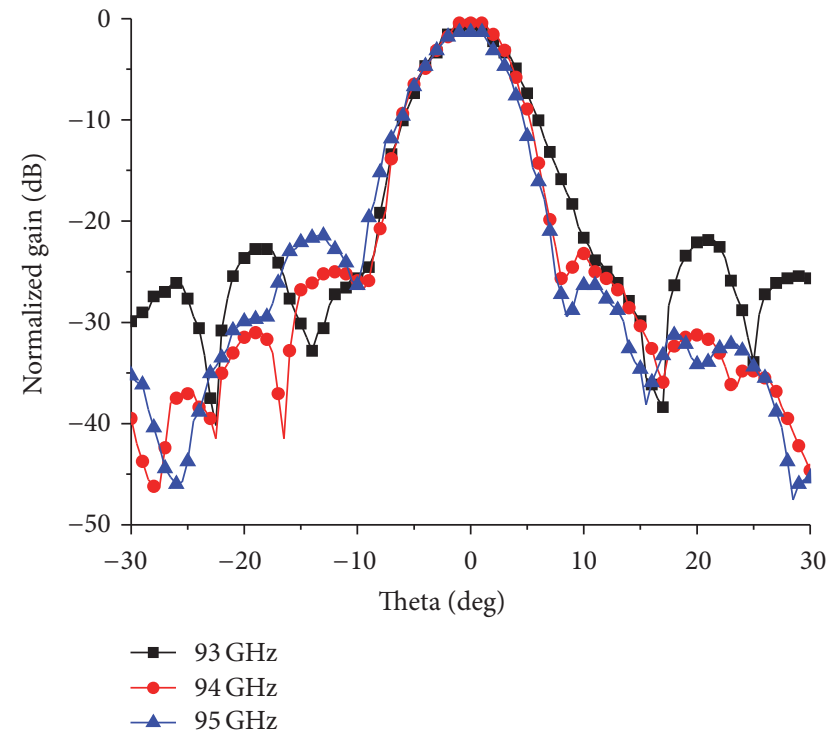

(a)

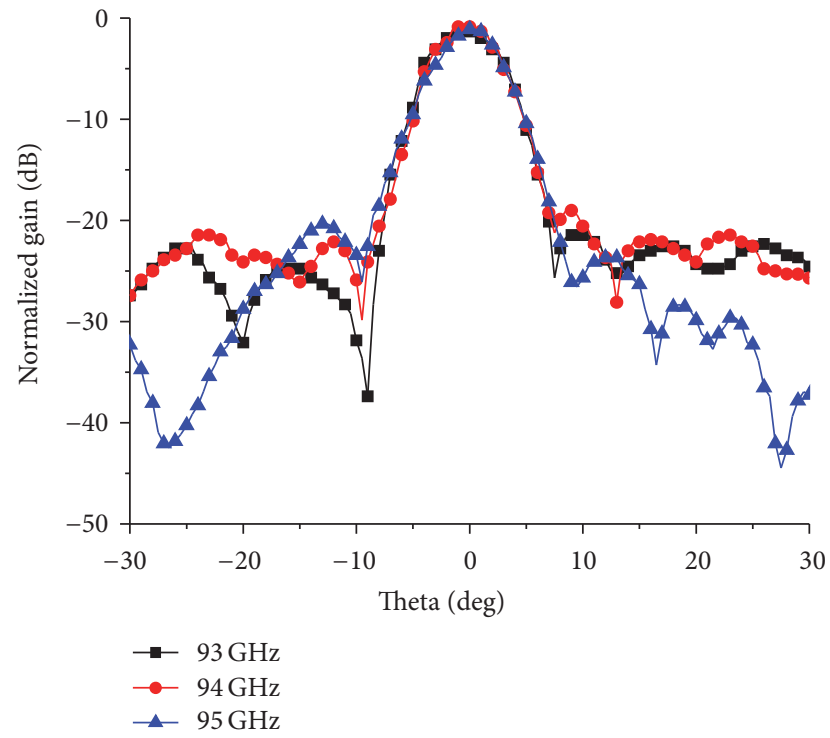

(b)

FIgURE 12: Measured radiation patterns at different frequencies. (a) E-plane; (b) H-plane.

\section{Experiment Results}

The photograph of the fabricated antenna is shown in Figure 9. As shown in Figure 10(a), the simulated and measured reflection coefficients are both less than $-10 \mathrm{~dB}$ from $93 \mathrm{GHz}$ to $95 \mathrm{GHz}$. Figure 10(b) shows the simulated and measured total efficiencies of the antenna, which can reach up to $75 \%$ and $62 \%$, respectively. There exists a $13 \%$ difference because of $1 \mathrm{~dB}$ insertion loss of the waveguide divider, which is not included in the simulation. Figures 11 and 12 present the simulated and measured radiation patterns at different frequencies. SLLs in both E-plane and $\mathrm{H}$-plane are less than $-20 \mathrm{~dB}$. The gain is about $26.5 \sim 28 \mathrm{dBi}$ within the band.

\section{Conclusion}

In this paper, a compact hybrid waveguide-SIW E-plane divider and an SIW 1-to-16-way unequal divider with phase compensating ability are introduced for W-band high efficiency and low SLL antenna array application. The simulated results are in good agreement with the measured ones. The return loss of the fabricated antenna is less than $-10 \mathrm{~dB}$, the 
gain is larger than $26.5 \mathrm{dBi}$, the total efficiency is up to $62 \%$, and the SLLs in both E-plane and H-plane are below -20 dB.

\section{Conflicts of Interest}

The authors declare that they have no conflicts of interest.

\section{Acknowledgments}

This work is supported by the National Natural Science Foundation of China under Grant nos. 61622105 and 61631012; the Science Foundation for Distinguished Young Scholars of Sichuan Province under Grant 2015JQO005; the Fundamental Research Funds for the Central Universities under Grant ZYGX2014Z008; and the Foundation for the Author of National Excellent Doctoral Dissertation of P. R. China under Grant 201338.

\section{References}

[1] Y. J. Cheng, Y. X. Guo, and Z. G. Liu, "W-Band large-scale high-gain planar integrated antenna array," IEEE Transactions on Antennas and Propagation, vol. 62, no. 6, pp. 3370-3373, 2014.

[2] N. Ghassemi, K. Wu, S. Claude, X. Zhang, and J. Bornemann, "Low-cost and high-efficient W-band substrate integrated waveguide antenna array made of printed circuit board process," IEEE Transactions on Antennas and Propagation, vol. 60, no. 3, pp. 1648-1653, 2012.

[3] X. H. Zhang, G. Q. Luo, and L. X. Dong, "Substrate integrated waveguide fed cavity backed slot antenna for circularly polarized application," International Journal of Antennas and Propagation, vol. 2013, Article ID 316208, 6 pages, 2013.

[4] S. Zhang, Z. Li, and J. Wang, "A novel SIW H-plane horn antenna based on parabolic reflector," International Journal of Antennas and Propagation, vol. 2016, Article ID 3659230, 7 pages, 2016.

[5] J. Wu, Y. J. Cheng, and Y. Fan, "Millimeter-wave wideband highefficiency circularly polarized planar array antenna," Institute of Electrical and Electronics Engineers. Transactions on Antennas and Propagation, vol. 64, no. 2, pp. 535-542, 2016.

[6] Y. J. Cheng and F. Xue, "Ka-band near-field-focused array antenna with variable focal point," IEEE Transactions on Antennas and Propagation, vol. 64, no. 5, pp. 1725-1732, 2016.

[7] R. S. Elliott and W. R. O'loughlin, "The design of slot arrays including internal mutual coupling," IEEE Transactions on Antennas and Propagation, vol. 34, no. 9, pp. 1149-1154, 1986.

[8] M. M. Zhou, Y. J. Cheng, and W. N. Huang, "Substrate integrated slot array antenna with required radiation pattern envelope," International Journal of Antennas and Propagation, vol. 2016, Article ID 4031029, 4 pages, 2016.

[9] S.-J. Park, D.-H. Shin, and S.-O. Park, "Low side-lobe substrateintegrated-waveguide antenna array using broadband unequal feeding network for millimeter-wave handset device," IEEE Transactions on Antennas and Propagation, vol. 64, no. 3, pp. 923-932, 2016.

[10] T. Li and W. Dou, "Broadband substrate-integrated waveguide T-junction with arbitrary power-dividing ratio," Electronics Letters, vol. 51, no. 3, pp. 259-260, 2015.

[11] B. Y. El Khatib, T. Djerafi, and K. Wu, "Three-dimensional architecture of substrate integrated waveguide feeder for fermi tapered slot antenna array applications," IEEE Transactions on Antennas and Propagation, vol. 60, no. 10, pp. 4610-4618, 2012.

[12] J. F. Xu, W. Hong, P. Chen, and K. Wu, "Design and implementation of low sidelobe substrate integrated waveguide longitudinal slot array antennas," IET Microwaves, Antennas and Propagation, vol. 3, no. 5, pp. 790-797, 2009.

[13] Y. J. Cheng, H. Xu, D. Ma, J. Wu, L. Wang, and Y. Fan, "Millimeter-wave shaped-beam substrate integrated conformal array antenna," IEEE Transactions on Antennas and Propagation, vol. 61, no. 9, pp. 4558-4566, 2013.

[14] Y. J. Cheng, W. Hong, and K. Wu, “94 GHz substrate integrated monopulse antenna array," IEEE Transactions on Antennas and Propagation, vol. 60, no. 1, pp. 121-129, 2012.

[15] J. Wu, Y. J. Cheng, and Y. Fan, "A wideband high-gain highefficiency hybrid integrated plate array antenna for V-band inter-satellite links," Institute of Electrical and Electronics Engineers. Transactions on Antennas and Propagation, vol. 63, no. 4, pp. 1225-1233, 2015.

[16] T. Kai, J. Hirokawa, and M. Ando, "A stepped post-wall waveguide with aperture interface to standard waveguide," in Proceedings of the IEEE Antennas and Propagation Society Symposium, vol. 2, pp. 1527-1530, June 2004.

[17] B. Cao, H. Wang, Y. Huang, J. Wang, and H. Xu, "A novel antenna-in-package with LTCC technology for W-band application," IEEE Antennas and Wireless Propagation Letters, vol. 13, pp. 357-360, 2014.

[18] J. Lee, J. Hirokawa, and M. Ando, "Transition to a highdielectric constant post wall waveguide from a standard waveguide by using a hollow cavity in a laminated substrate," in Proceedings of the IEEE Antennas and Propagation Society International Symposium (APS '06), pp. 1613-1616, July 2006. 


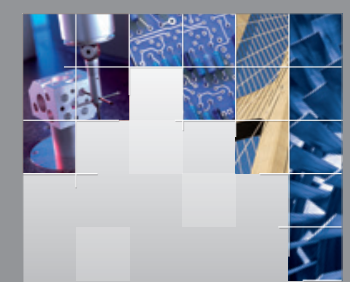

\section{Enfincering}
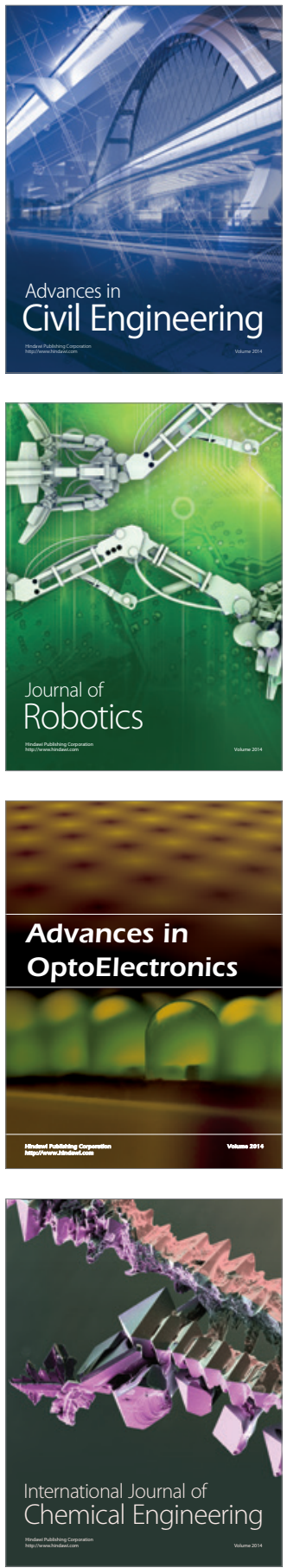

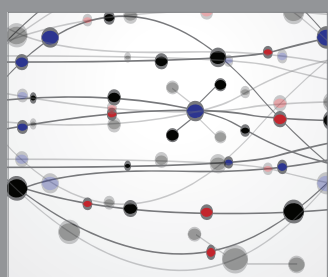

The Scientific World Journal

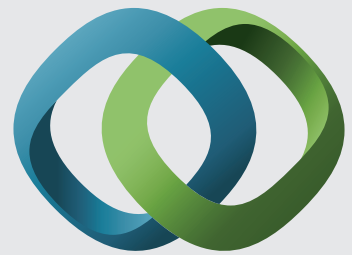

\section{Hindawi}

Submit your manuscripts at

https://www.hindawi.com
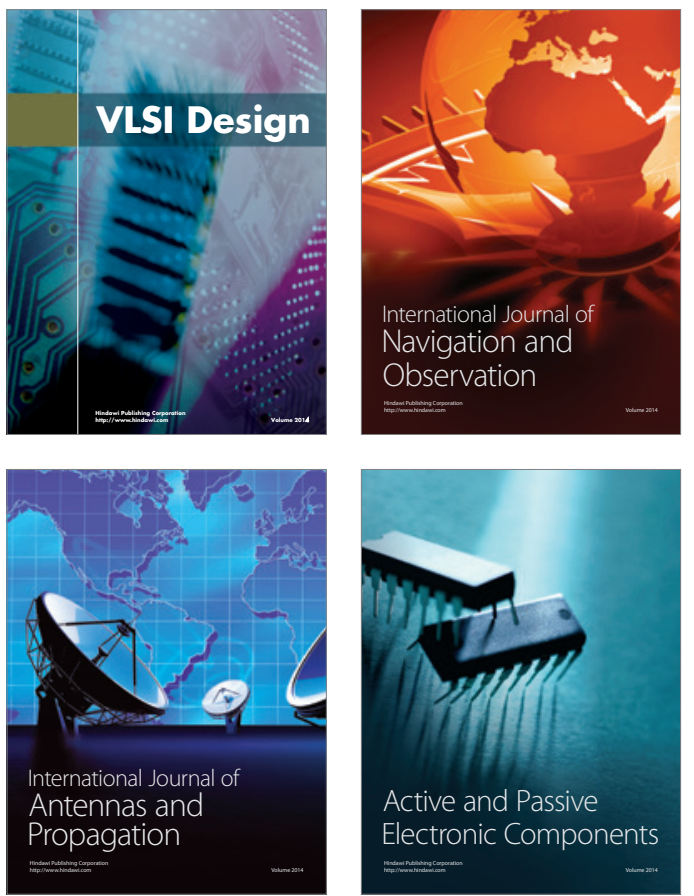
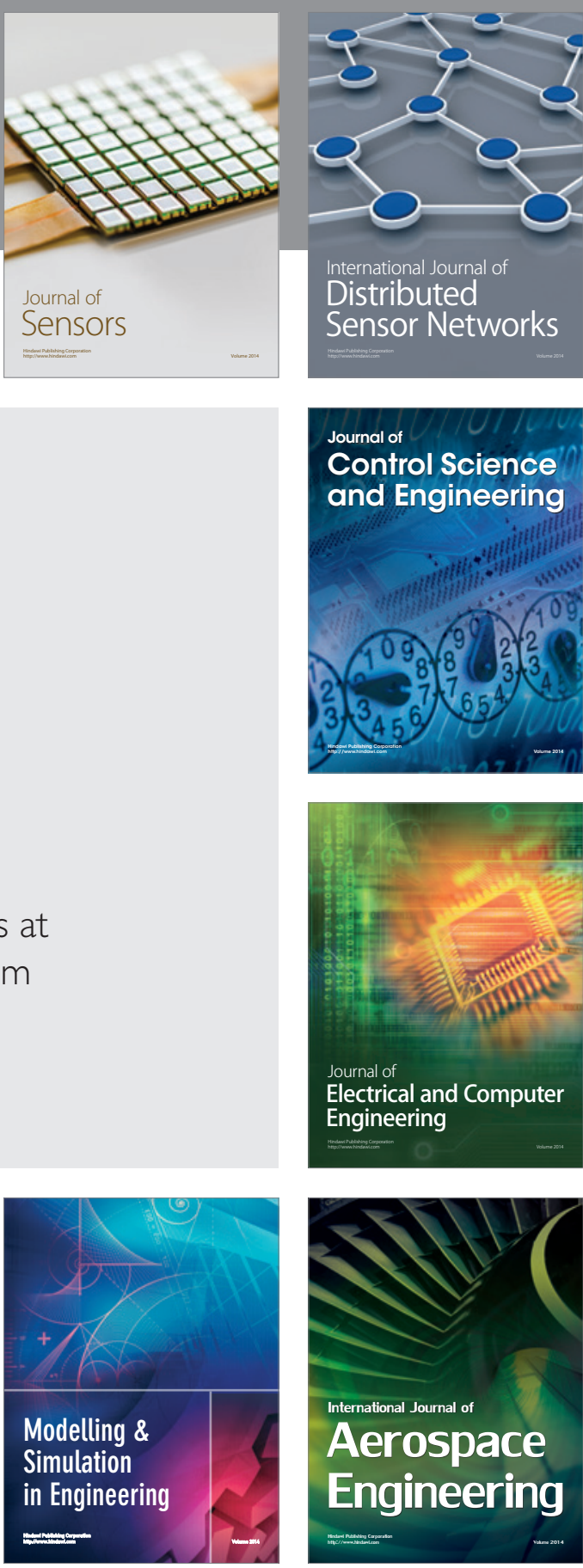

International Journal of

Distributed

Sensor Networks

$-$

Joumal of

Control Science

and Engineering
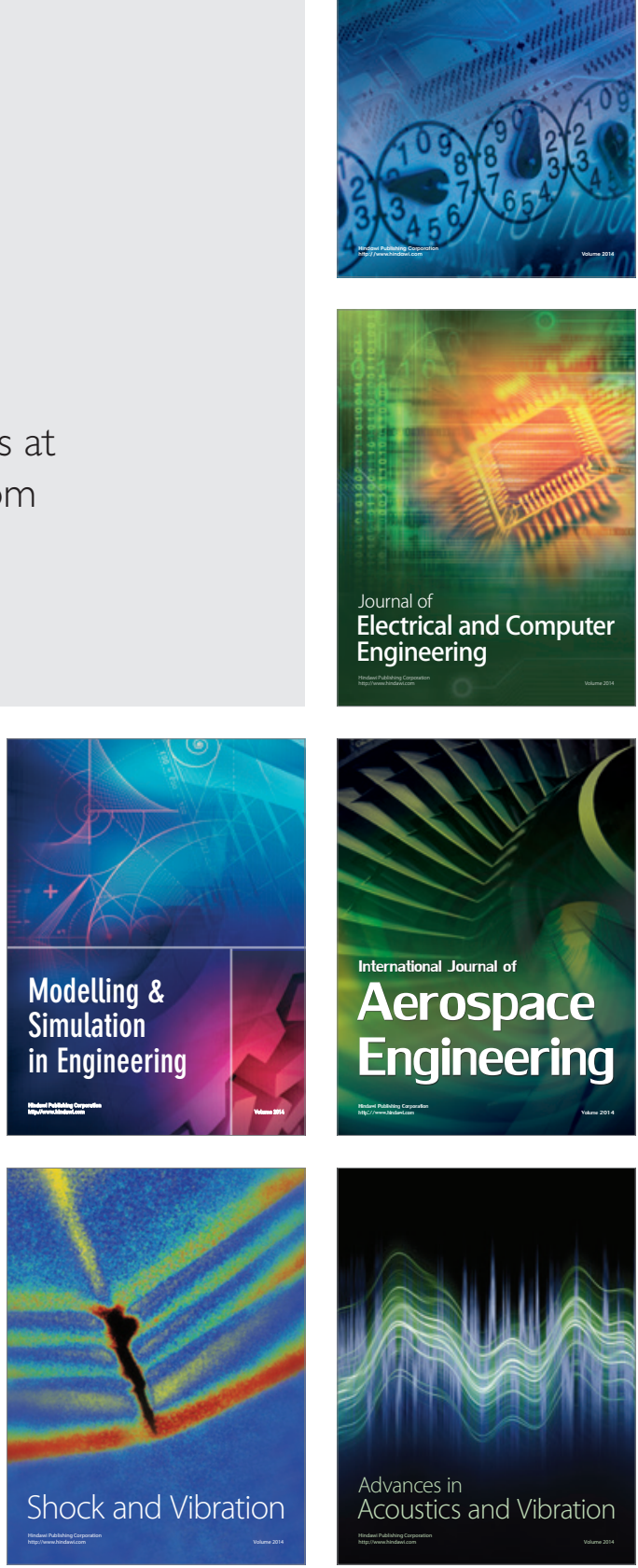